\title{
AFYON-SANDIKLI JEOTERMAL ALANINDA DÜŞEY ELEKTRİK SONDAJ (DES) ARAŞTIRMASI VE KUYULARIN FİİKSEL ÖZELLÍKLERİ
}

\author{
M.Nuri DOLMAZ ${ }^{\text {, Bilal ŞAHİN² }}{ }^{2}$ H. Evrim TÜTÜNSATAR ${ }^{*}$, Çağlayan BALKAYA
}

${ }^{1}$ Süleyman Demirel Üniversitesi, Mühendislik Fakültesi, Jeofizik Mühendisliği Bölümü, Isparta, Türkiye

${ }^{2}$ Süleyman Demirel Üniversitesi, Fen Bilimleri Enstitüsü, Isparta, Türkiye

${ }^{3}$ Isparta Uygulamalı Bilimler Üniversitesi, Gönen Meslek Yüksekokulu, Gönen/Isparta, Türkiye

\begin{tabular}{|c|c|}
\hline Anahtar Kelimeler & Öz \\
\hline $\begin{array}{l}\text { Sandıklı, } \\
\text { Jeotermal, } \\
\text { Modelleme, } \\
\text { Elektrik Özdirenç. }\end{array}$ & 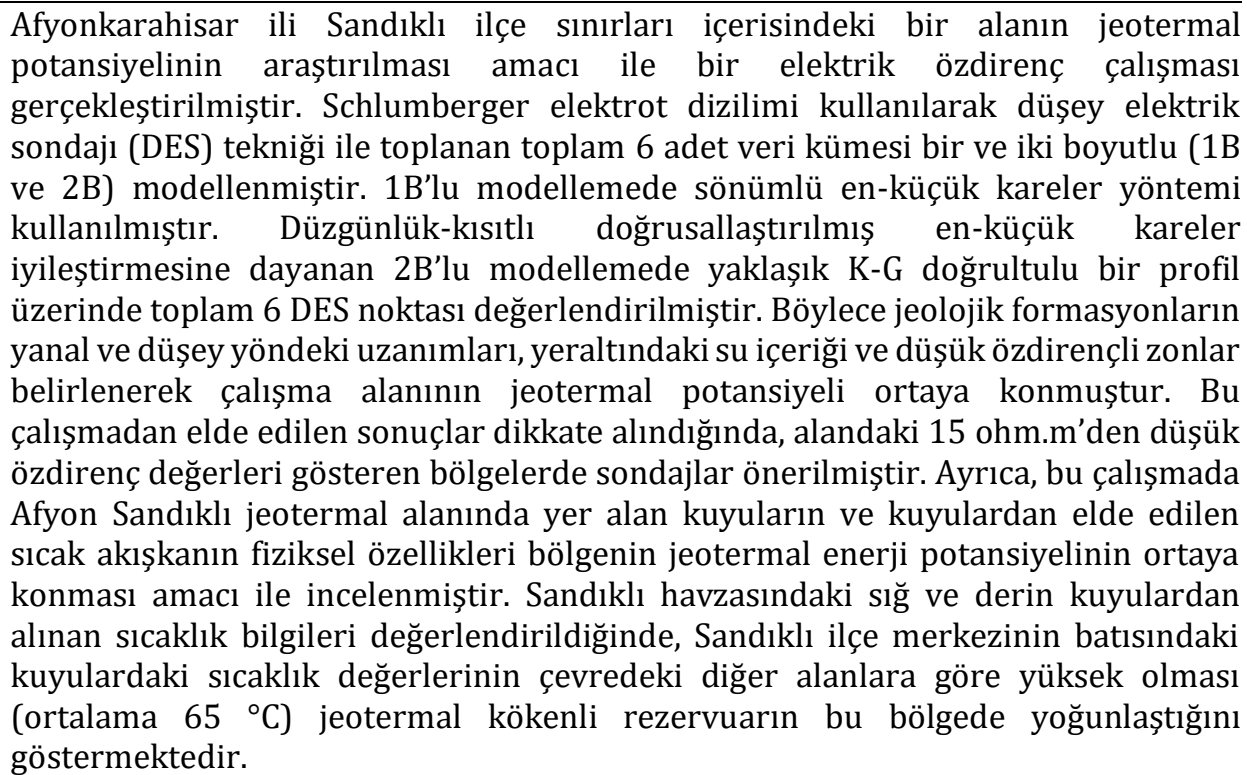 \\
\hline
\end{tabular}

\section{VERTICAL ELECTRICAL SOUNDING (VES) INVESTIGATION AND PHYSICAL PROPERTIES OF THE WELLS IN AFYON-SANDIKLI GEOTHERMAL AREA}

\begin{tabular}{l}
\hline Keywords \\
\hline Sandıkl, \\
Geothermal, \\
Modelling, \\
Resistivity.
\end{tabular}

\footnotetext{
* ilgili yazar / Corresponding author: evrimtutunsatar@isparta.edu.tr, +90-246-281-2300
}

\begin{abstract}
An electrical resistivity study was carried out to investigate the geothermal potential of an area in Sandikll, Afyonkarahisar. A total of 6 datasets collected by vertical electrical sounding (VES) technique using Schlumberger electrode array was modelled in one and two dimensions (1D and 2D). A damped least-squares method is used in 1D modelling. In 2D modelling based on smoothness-constrained linearized least-squares optimization, 6 VES points were evaluated on a profile with approximately $\mathrm{N}-\mathrm{S}$ direction. The geothermal potential of the study area was investigated by determining lateral and vertical directions of the geological formations, groundwater content and low resistivity zones. As the results obtained from the study are taken into consideration, drillings have been proposed in the regions where the resistivity values are less than $15 \mathrm{ohm} . \mathrm{m}$. Physical properties of wells and hot fluids obtained from wells in Sandıklı, Afyon geothermal area were investigated in order to reveal the geothermal energy potential of the region. When the temperature values obtained from shallow and deep wells in Sandıklı basin are evaluated, the temperature values in the wells directed to the west of Sandiklı town center are higher than the other surrounding areas (average $65^{\circ} \mathrm{C}$ ). This situation indicates that geothermal-originated reservoir is concentrated in this region.
\end{abstract}


Öngür (1973) tarafından Sandıklı yerleşim merkezi ve civarının jeolojisi 1/25000 ölçekli olarak çalışılmıştır. Çalışmasında, jeomorfolojik ve tektonik özelliklere ayrıntılı olarak yer verilmiştir. Sonuç olarak da hidrojeolojik ve jeotermal yönden jeofizik çalışmalarının yapılmasının gerekliliği ve önemi vurgulamıştır.

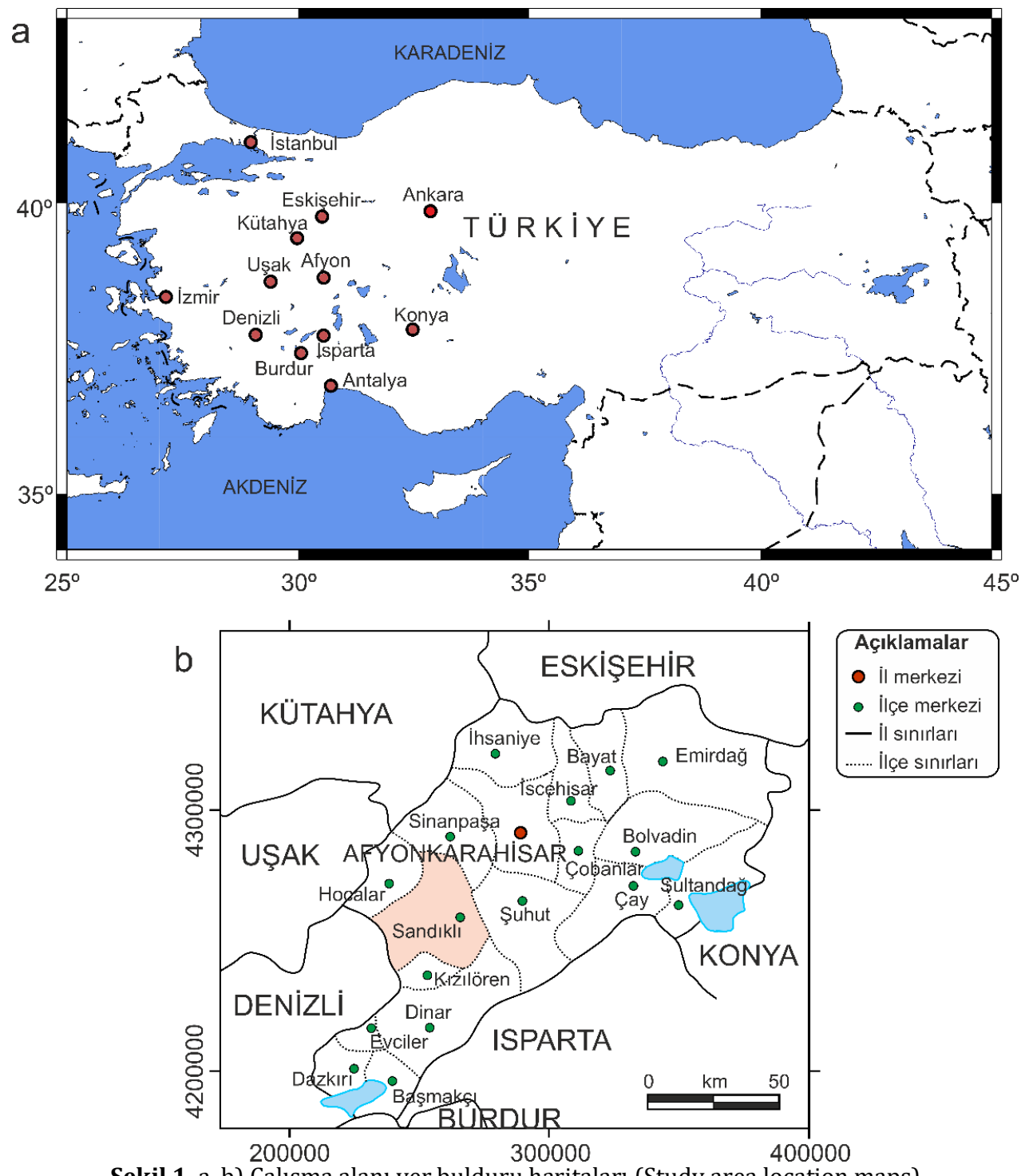

Şekil 1. a, b) Çalışma alanı yer bulduru haritaları (Study area location maps)

Yenal vd. (1975) tarafından Sandıklı kaplıcası ile ilgili yapılan çalışmada, yörede bulunan sıcak su kaynaklarının kimyasal tahlil sonuçlarına göre; sular alkali, toprak alkali-acı ve bikarbonatlı sular olarak üç gruba ayrılmıştır. Tıbbi açıdan değerlendirmelerin de yeraldığı çalışmada, ileri aşamaya ulaşmayan romatizma vb hastalıkların terapötik tedavilerinde sıcak suların çok yararlı olduğu belirtilmiştir.

Afşin (1991) tarafından Sandıklı Kuruçay ovası ve Hüdai kaplıcasının ayrıntılı olarak hidrojeolojisi incelenmiştir. 450 km2 lik bir alanda çalışılan inceleme sahasının temelini, Paleozoyik yaşlı epimetamorfitlerin oluşturduğu, bunların üzerine gelen birimlerin Mesozoyik ve Senozoyik boyunca Kuvaternere kadar yer yer kesikli olarak devam ettiği savunulmuştur. İnceleme alanına düșen yıllık ortalama yağış miktarının 474,93 mm, gerçek buharlaşma-terlemenin 380,74 mm olduğu, serbest ve basınçlı akiferlerde yeraltısuyu akım yönünün GD'dan KB'ya doğru olduğu belirlenmiştir. Hüdai kaplıcasında; sıcak ve mineralli su kaynaklarının K-G ve D-B doğrultusunda uzanan fayların birbirini kestiği noktalarda oluştuğu, sıcaklıklarının 46,5-70 ${ }^{\circ} \mathrm{C}$, debilerinin ise 87,0-91,5 l/s arasında değiștiği belirlenmiștir.

Afşin ve Canik (1996) tarafından gerçekleştirilen çalışmasında ise, Sandıklı yerleşim merkezinde yeralan Hüdai kaplıcası detaylı olarak incelenmiştir. Hüdai sıcak ve mineralli su kaynaklarının K-G ve D-B yönünde uzanan fayların kesişme noktalarında açığa çıktığını ve kaynakların sıcaklık, pH, toplam debi ve toplam çözünmüş madde miktarlarının sırasıyla $62^{\circ} \mathrm{C}-68^{\circ} \mathrm{C}, 6.2-7.5,87-91.5 \mathrm{l} / \mathrm{s}$ ve mineral değerinin $1360-1750 \mathrm{mg} / \mathrm{l}$ arasında değiștiği belirlenmiştir. Ayrıca, kimyasal bileșimleri nedeniyle tedavi edici nitelikte olan kaynakların Ca, HCO3, SO4, SiO2 'li 
radyoaktif sıcak ve mineralli sular olduğu ifade edilmiş ve kaynakların farklı jeotermometreler kullanarak ölçülen hazne kaya sıcaklığının $100{ }^{\circ} \mathrm{C}-250{ }^{\circ} \mathrm{C}$ arasında değiştiği belirtilmiștir.

Ölmez vd. (2000) tarafından Afyon- Sandıklı Hüdai kaplıcası çevresinde yapılan jeofizik çalışmaları sonucu AFS-3 nolu sondaj lokasyonu önerilmiştir.

Hamut ve Şengüler (2001) tarafından hazırlanan Afyon-Sandıklı (Hüdai) jeotermal sahası koruma alanları raporunda 1994 yılında yapılan AFS-1 ve AFS-2 sondaj verileri ile 2000 yılında yapılan AFS-3, AFS-4, AFS-5 ve AFS-6 sondaj verilerini baz alarak koruma alanları belirlenmiștir.

Koçyiğit vd. (2001) tarafından Batı Anadolu horst-graben sisteminin en doğu kesiminde yeralan Sandıklı grabeninin neotektonik özellikleri ve depremselliği incelenmiştir. Sandıklı grabeninin, verev atımlı normal faylarla (Akın, Kemerkayatepe, Ballık fayları) Miyosen sonunda gelişmeye başlamış, Geç Pliyosende başlayan ve Kuvaternerde de devam eden faylanmalarla (Gökçealan, Sandıklı, Maymunkayası ve Hüdaihamamı fayları) bugünkü geometrisini kazandığı ve bölgedeki fayların jeolojik olarak diri olduğu belirtilmiştir.

Özpınar vd. (2002) tarafından Sandıklı civarındaki volkanitlerin yayılımını belirlemek amacıyla öncelikle, $250 \mathrm{~km} 2$ lik alanda 1/25 000 ölçekli jeolojik haritası yapılmış, daha sonra bölgedeki tüflerin teknolojik özelliklerinin saptanmasına yönelik laboratuar çalışmaları gerçekleştirilmiştir.

Erdoğan vd. (2004) tarafından Sandıklı bölgesindeki temel birimler ayrıntılı olarak incelenmiş ve metamorfik temelde mikaşist, kuvarsit, fillit ve mermerlerin egemen oldukları belirlenmiştir.

Karamanderesi (2004) tarafından Afyon Sandıklı Hüdai Kaplıcası sıcak su sondajlarının (AFS-11, AFS-12, AFS-13 ve AFS-14) lokasyonları belirlenerek gerçekleşmesi sağlamıştır. Karamanderesi (2008) tarafından AFS-14 nolu sondaj lokasyonu belirlenerek sondajın takibi gerçekleştirmiştir.

Güngör vd. (2004) çalıșmalarında, Sandıklı (Afyon) bölgesinde bulunan Erken Kambriyen yașlı Kocayayla Grubu'nun deformasyon özelliklerini tanımlamışlardır. Kocayayla Grubu 2500 m kalınlığa ulaşan Erken Kambriyen yaşlı bir istif ile temsil edilmektedir. Bu istifin en altında, Erken Kambriyeni simgeleyen iz fosilleri içeren fillit arakatkılı kuvars kumtaşlarından oluşan Celiloğlu birimi bulunmaktadır. Göğebakan birimi, çört mercekleri, mafik volkanit ve kanal dolgusu çakıltaşı arakatkıları içeren metapelitler ve metapsammitlerden oluşur ve uyumlu bir dokanak boyunca Celiloğlu biriminin üstünde yeralır. Göğebakan birimi, tortul arakatkılar içeren riyolitlerden oluşan Kestel Çayı volkanitleri ile yanal ve düşey yönde geçişlidir. Taşoluk biriminin fillit arakatkıları içeren sarı renkli kumtaşlarından oluşup uyumlu bir dokanak boyunca Kestel Çayı volkanitlerinin üstünde Kocayayla Grubunun en üst birimini oluşturduğunu savunmuştur.

Memiş (2010) tarafından Afyon Sandıklı Hüdai jeotermal alanının hidrojeokimyasal özellikleri belirlenerek iz element kirliliği incelenmiştir. Çalışma alanındaki jeotermal sular Na-SO4-HCO3 tipli sular, yeraltısuları ise CaHCO3 tipli sular olarak sınıflandırılmıştır. Jeotermal sularda hakim iyon dizilimi, katyonlar için $\mathrm{Na}+\mathrm{K}>\mathrm{Ca}>\mathrm{Mg}$, anyonlar için SO4>HCO3>Cl olarak belirlenmiştir. İyon değişim diyagramları, jeotermal suların yeraltında uzun süre kalmadığını göstermektedir. Hüdai jeotermal alanındaki suların rezervuar sıcaklıkları silika jeokimyasal termometreleri ile $85-120^{\circ} \mathrm{C}$ arasında hesaplanmıștır. Entalpi-silika ve entalpi-klorür karıșım modelleri sırasıyla $108-134{ }^{\circ} \mathrm{C}$ ve $98-120^{\circ} \mathrm{C}$ rezervuar sıcaklıkları önermektedirler.

Aksever (2011) tarafından yapılan çalışmada yarı kapalı havza özelliğindeki Afyon Sandıklı havzasının jeolojik, hidrojeolojik ve hidrojeokimyasal özellikleri ayrıntılı olarak ele alınmıştır. Sandıklı havzasında en önemli sorunun yoğun tarımsal faaliyetler sonucu aşırı yeraltısuyu çekimi olduğu ve bu nedenle sürdürülebilir kullanım için su potansiyelinin belirlenmesinin büyük önem taşıdığı ifade edilmiştir. Çalışma alanının orta kesimlerindeki hazne kayacın kuvarsit ve kireçtaşı olan Hüdai sıcak ve mineralli su kaynağının ise Na-SO4'lı sular sınıfında olduğu belirtilmiștir. Özellikle Al, Fe, Ba ve Cd elementlerinde kaya-su etkileșimi ve sıcak su akiferi ile etkileșimde olan noktalarda yersel artışlar gözlenmektedir.

Oğuz (2011) tarafından Sandıklı'da jeotermal alanın temelini oluşturan Paleozoyik yaşlı kayaçların sıcak suların ana rezervuarı olduğu ifade edilmiştir. Afyon Paleozoyik grubu olarak tanımlanan birimin metamorfize olmuş kesimi Kestel Formasyonu olarak adlandırılmıştır. Paleozoyik yaşlı kayaçların en üst seviyelerini Hüdai kuvarsit üyesi oluşturmaktadır. Bölgede yapılan arama ve üretim sondajlarından AFS-14 nolu sondaja ait kırıntı örnekleri üzerinde yapılan XRD analiz sonuçlarına göre; dolomit, kuvars, feldispat, kil mineralleri, zeolit, klorit, illit ve mika birliktelikleri saptanmıștır. Bu verilerden hareketle, bölgede potasik - albitik alterasyon ve $70{ }^{\circ} \mathrm{C}-110{ }^{\circ} \mathrm{C}$ lik bir jeotermal ve/veya hidrotermal akışkan etkilerinden söz edilebileceği sonucuna varılmıștır. 
Dolmaz (2014) tarafından İç Batı Anadolu'daki sismik belirtisi olmayan zon ile Sandıklı alanının jeotermal yapısı arasındaki ilişki ile ilgili çalışma yapılmıştır. Yüksek sismik aktiviteli alanlardaki sismik olmayan zonlar ile jeotermal yapı arasında bir ilişki bulunduğu belirtilmiş ve sismik olmayan bu rejyonal zonlarda jeotermal yapılar hakkında arama çalışmalarının yapılması gerektiği vurgulanmıştır. Dolmaz (2014)'e göre, Sandıklı yerleşimi de sismik olmayan Uşak-Afyon zonunda bulunduğu ve Sandıklı'nın jeotermal yapısının Afrika-Avrasya litosferik plaka sınırlarındaki tektonik hareketler ile ilișkili kontrol edildiği belirtilmiștir. Sismik aktif olmayan bu zonun kuzeyinde Gediz güneyinde ise Dinar son yüzyıl içersinde büyük depremlere maruz kalmıştır. Sismik aktivite görülmeyen Uşak-Afyon zonunda ise elde edilen sığ Curie derinlikleri, yüksek ısı akısına sahip alanlar, yüksek düşey ısıl gradiyentler, bölgede üst kabuktaki incelme ve yüksek kondüktiviteli alt kabuğun sığlaşması büyük bir termal yapıdan kaynaklanmaktadır. Güneyde Dinar ve kuzeyde Gediz gibi iki rejyonal aktif sismik alan arasında kalan ve Sandıklı'yı da içine alan düşük sismik aktivitenin bulunduğu Uşak-Afyon zonu sığ Curie derinlikleri ve yüksek ısı akısı ile özdeşleşmiş olup rejyonal bir jeotermal yapıya sahiptir (Dolmaz vd., 2005; Dolmaz, 2014).

\section{Materyal ve Yöntem (Material and Method)}

\section{1. Çalışma Alanının Jeolojisi (The Geology of Study Area)}

Hüdai jeotermal alanı, Sandıklı ilçesi sınırları içerisinde Afyon iline $65 \mathrm{~km}$ uzaklıkta ve güneybatısında bulunmaktadır (Şekil 1 ve 2). Sandıklı ilçesi ve civarında Hamamçay kaynakları adı altında birçok sıcak su kaynağı bulunmaktadır. Tabanda Koçgazi fillit üyesi çok düşük metamorfizmalı bej, kahvemsi bej renkli ince taneli kumtaşı, siyah ve kahve-mor renkli silttaşı ve bunlarla yer yer arakatkılı metabazik sillerinden meydana gelmektedir (Şekil 2). Alt Kambriyen yaşlı Hüdai Formasyonu çoğunlukla kuvarsitlerden meydana gelmekte ve yer yer şistlerle ardalanmalı olarak bulunmaktadır. Jeotermal sistemin örtü kayacını oluşturan Seydişehir Formasyonu miltaşı, şeyl ve kuvars kumtaşı ardalanmasından oluşmaktadır. İstifin alt düzeylerinde ince, alacalı renkli ve yumrulu kireçtaşı bantları izlenmektedir (Afşin 1991; Özgül vd., 1991; Günay vd., 1995; Gürsu ve Göncüoğlu, 2005). Üst Triyas-Alt Jura yaşlı Karatepe Formasyonu çakıltaşı, kumtaşı ve silttaşlarından oluşur. Derealanı Formasyonu Alt Jura yaşlı olup, marnlı kumtaşı ile başlayıp, üste doğru kumlu, siltli ve killi kireçtaşı, kumlu kireçtaşı ardalanması şeklinde devam etmektedir. Üst Jura-Alt Kratese yaşlı olan Akdağ Formasyonu ise masife yakın breşik kireçtaşları ile başlar, yukarıya doğru çıkıldıkça çört bantları bulunan kireçtaşları ve daha üstte çört oranı artarak dolomitik özellikte kireçtaşları ile devam eder (Afşin, 1991; Özpınar, 2008). Sandıklı Formasyonu, Üst Miyosen yaşlı Akin tüf üyesi, Üst Miyosen yaşlı Sandıklı üyesi ve Pliyosen yaşlı Hamamçayı üyesinden oluşmaktadır. Kuvaterner yaşlı traverten ve alüvyon en genç çökellerdir (Afșin,1991; Özgül vd., 1991; Dean ve Özgül, 1994; Kozlu ve Göncüoğlu, 1995; 1997; Gürsu ve Göncüoğlu, 2005; Özpınar, 2008). Sandıklı jeotermal sahasının ısı kaynağını bölgedeki volkanikler oluştururken, Paleozoik yaşlı metamorfikler içindeki çatlak ve kırıklı şistler ve kuvarsitler rezervuar kayacını meydana getirir (Şekil 2).

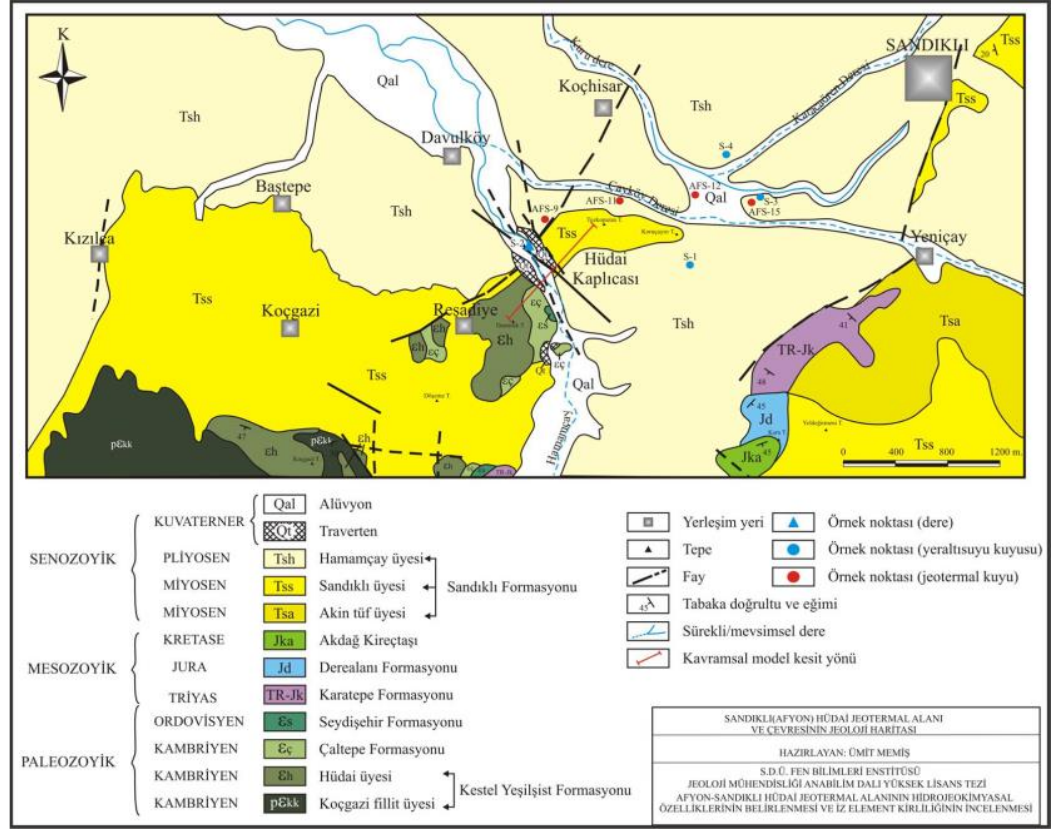

Şekil 2. Sandıklı ve çevresinin jeoloji haritası (Memiș, 2010) (The geological map of Sandıklı and its surrounding) 


\subsection{Doğru Akım Özdirenç (DAÖ) Yöntemi (Direct Current Rezistivity (DCR) Method)}

DAÖ yöntemi, görece maliyetinin düşük olması, kolay uygulanabilmesi ve oldukça verimli sonuçlar üretmesi nedeniyle arama jeofiziğinde özellikle; hidrojeoloji, jeotermal, maden/mineral araștırmalarında ve arkeolojik prospeksiyon çalıșmalarında en çok uygulanan yer elektrik yöntemdir. Bu yöntemde, genel olarak yeriçinin jeolojik yapısı katmanların elektrik iletkenlik özelliklerinden yararlanarak araştırılır. Bu amaç için, yer yüzeyi boyunca gerçekleștirilen görünür özdirenç ölçümleri; iki elektrot yardımıyla yere elektrik akımının uygulanması ve diğer iki elektrot arasında oluşan potansiyel farkının ölçülmesi esasına dayanır (Șekil 3). Görünür özdirenç verileri, sondaj, profil ve sondaj-profil olarak tanımlanan üç farklı ölçü tekniği kullanılarak elde edilir ve toplanan veri kümeleri bir, iki ve üç boyutlu (1B, 2B ve 3B) ters çözüm teknikleriyle değerlendirilebilir.

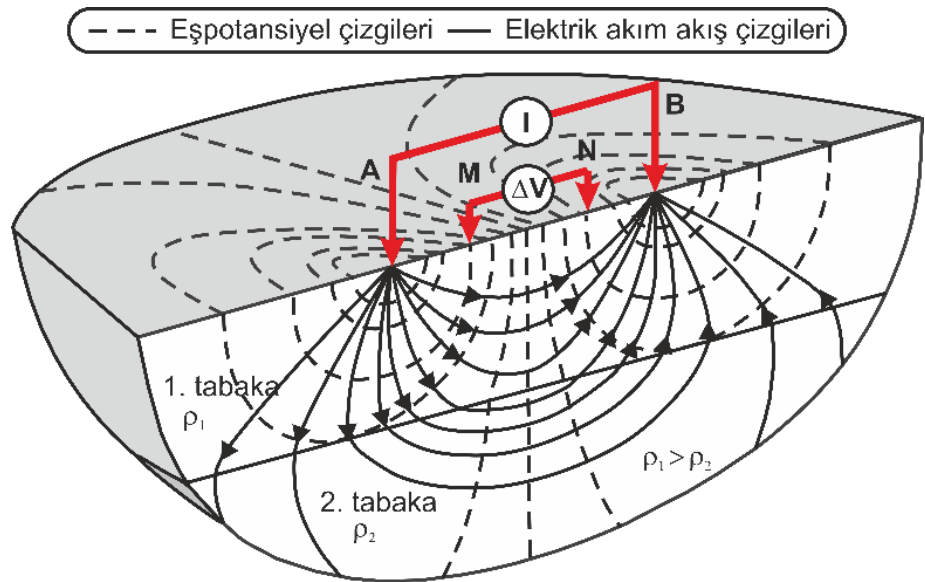

Şekil 3. DAÖ yönteminin temel çalışma prensibi (Seidel ve Lange, 2007'den düzenlenmiştir) (The basic application principle of DCR method)

Bu çalışmada, DAÖ yöntemi, DES tekniği kullanılarak toplam 6 profil üzerinde Schlumberger elektrot dizilimiyle gerçekleștirilmiştir. Görünür özdirenç veri kümeleri, genel olarak, minimum ve maksimum $A B / 2$ değerleri sırasıyla $10 \mathrm{~m}$ ve $1200 \mathrm{~m}$ olan doğrultular üzerinde toplanmış ve nicel yorum için sönümlü en-küçük kareler yöntemiyle 1B ters çözüm uygulanmıștır. Değerlendirmede, başlangıç modeli olarak her bir DES belirtisindeki ortalama görünür özdirenç değerleri kullanılırken, Jacobian dizeyleri her bir yinelemede ileri fark yöntemiyle hesaplanmıştır. Dizey terslemeleri için eşlenik türev en-küçük kareler yöntemi (Bjorck, 1996) kullanılmıştır. Ayrıca, yaklaşık K-G doğrultulu bir profil üzerinde bulunan toplam 6 DES noktası düzgünlük-kısıtlı doğrusallaştırılmış en-küçük kareler iyileştirmesine dayanan bir ters çözüm tekniği (Uchida ve Murakami, 1990) ile 2B olarak değerlendirilmiştir. Kullanılan 2B ters çözüm algoritması, ölçülen ve düz çözümde sonlu elemanlar yöntemiyle hesaplanan görünür özdirenç veri kümeleri arasındaki çakışmazlığı en küçükleyerek her bir blokun özdirenç değerini yinelemeli olarak hesaplamaktadır. Algoritmanın jeotermal (Özürlan vd., 2006), arkeolojik prospeksiyon (El-Qady vd., 1999; Candansayar ve Başokur, 2001) ve çevre jeofiziği (Balkaya vd., 2009; Balkaya vd., 2012; Kaya vd., 2015) çalışmalarında başarılı uygulamaları bulunmaktadır.

\section{Araştırma Bulguları (Research Findings)}

Arazide yapılan çalıșmalardan elde edilen bütün sonuçların değerlendirilmesi, çalıșma sahasında jeotermal ortamın olup olmayacağına yönelik olmuştur. Bu kapsamda Afyon Sandıklı bölgesinde yer alan çalışma sahaları içerisinde jeotermal potansiyelin araştırılmasına yönelik aşamalı olarak bölgede daha önce açılmış kuyulardan alınan sıcaklık değerleri değerlendirilmiş ve jeofizik yöntemlerden DAÖ yöntemi uygulanmıştır.

Araştırma sahasında çalışmalar genel olarak iki aşamada gerçekleştirilmiştir. Öncelikli olarak açılan kuyuların lokasyonları belirlenmiş (Şekil 4) ve lokasyonları belirlenen birçok kuyudan sıcaklık değerleri alınmıștır. İnceleme alanındaki kuyuların koordinatları ve elde edilen sıcaklık değerleri sınıflandırılmış olarak renk ölçeği ile Tablo 1' de verilmektedir. Sandıklı ilçesi ve civarında bulunan sığ ve derin kuyulardan alınan sıcaklık bilgileri değerlendirildiğinde, çalıșma alanı içerisinde sıcaklıkların homojen ve düzenli bir dağılım göstermediğini söyleyebiliriz. Sandıklı ilçe merkezinin batısındaki kuyulardaki sıcaklık değerleri çevredeki diğer alanlardaki kuyulara göre göreceli olarak daha yüksektir ve ortalama $65{ }^{\circ} \mathrm{C}$ seviyelerindedir. Buna rağmen yüksek isıda akışkan bulunduran kuyulara yakın mesafedeki düşük sıcaklık $\left(18-25{ }^{\circ} \mathrm{C}\right.$ arası) içeren soğuk su kuyularının olmasında; bu kuyuların derinliklerinin sığ olması, kuyu teçhiz planları (kuyu çapı, boru dizaynı, çakıllama vb.) ve çıkarılan akışkanın kullanım amaçları (tarımsal sulama, hayvancılık vb.) önemli rol oynamaktadır. 


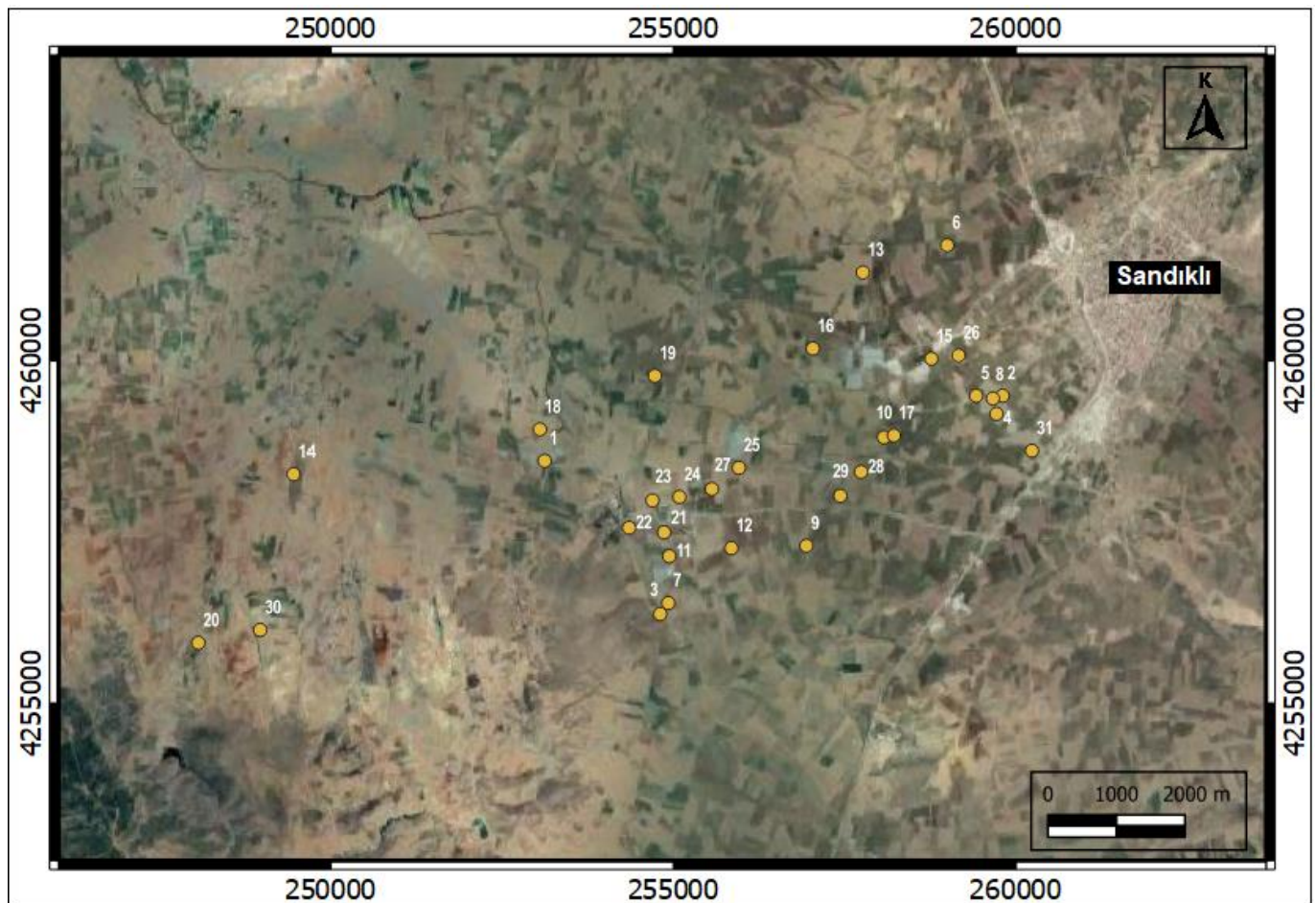

Şekil 4. Çalıșma alanındaki kuyuların konumları (Kuyu numaraları için Tablo 1'e bakınız) (The location of wells in study area)

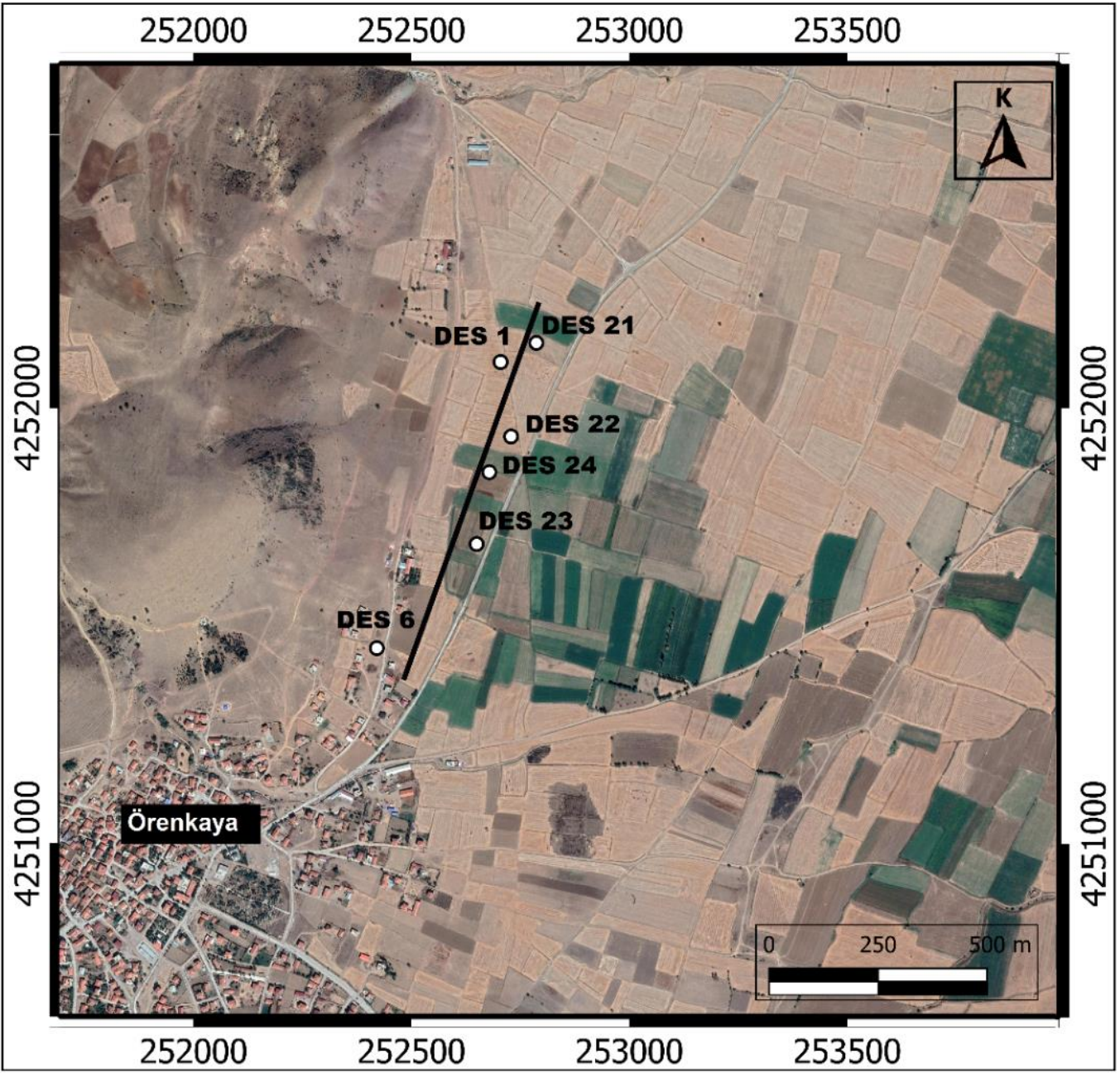

Şekil 5. 2B ters çözümde kullanılan DES noktalarının çalışma alanı üzerindeki konumları (The locations of VES points used in 2D inversion) 
Tablo 1. Şekil 4'te konumları verilen kuyuların sıcaklık durumuna göre sınıflandırılması (The classification of wells given in Figure 4 according to their temperature conditions)

\begin{tabular}{|c|c|c|c|c|}
\hline \multirow{2}{*}{$\begin{array}{l}\text { KUYU } \\
\text { NO }\end{array}$} & \multirow[t]{2}{*}{ KUYU ADI } & \multicolumn{2}{|c|}{ KOORDİNATLARI } & \multirow{2}{*}{$\begin{array}{c}\text { SICAKLIK } \\
\left({ }^{\circ} \mathrm{C}\right) \\
\end{array}$} \\
\hline & & $\mathbf{X}$ & $\mathbf{Y}$ & \\
\hline 1 & $\begin{array}{l}\text { Halil Hilmi Kırkpınar } \\
\text { kuyusu }\end{array}$ & 4258633 & 253109 & 13.3 \\
\hline 2 & $\begin{array}{c}\text { Belediye Terfi merkezi içme } \\
\text { suyu }\end{array}$ & 4259587 & 259798 & 14.3 \\
\hline 3 & Çelik Turşu Fabrikası-1 & 4256396 & 254797 & 14.6 \\
\hline 4 & Sandıklı Tarım kuyusu & 4259321 & 259708 & 16.4 \\
\hline 5 & Mehmet Diker kuyusu & 4259586 & 259412 & 16.4 \\
\hline 6 & Hidayet Kıymaz kuyusu & 4261785 & 258989 & 17.8 \\
\hline 7 & Çelik Turşu Fabrikası-2 & 4256556 & 254915 & 18.2 \\
\hline 8 & ASS-1 & 4259546 & 259656 & 18.5 \\
\hline 9 & Sipsim 2 nolu içme kuyusu & 4257393 & 256932 & 22.3 \\
\hline 10 & Selçiköyü kuyu güneyi & 4258978 & 258064 & 24.6 \\
\hline 11 & Kadığlu kuyusu & 4257241 & 254930 & 26.4 \\
\hline 12 & İrfan Coşkun kuyusu & 4257359 & 255837 & 26.6 \\
\hline 13 & Ali Yağcı kuyusu & 4261388 & 257758 & 27.9 \\
\hline 14 & Beştepe kuyusu & 4258439 & 249464 & 28.6 \\
\hline 15 & Sandıklı Beton kuyusu & 4260127 & 258758 & 29.1 \\
\hline 16 & Şaban kuyusu & 4260276 & 257026 & 36.1 \\
\hline 17 & Çakıcının kuyusu & 4259005 & 258211 & 38.8 \\
\hline 18 & İshak Özbek kuyusu & 4259094 & 253039 & 46.5 \\
\hline 19 & İshak Özbek Koç 1 & 4259877 & 254719 & 51.4 \\
\hline 20 & Aldosan 2 kuyusu & 4255974 & 248074 & 61 \\
\hline 21 & Mevlüt Özçınar & 4257589 & 254854 & 62.7 \\
\hline 22 & AFS-2 & 4257656 & 254342 & 66.8 \\
\hline 23 & AFS-9 & 4258055 & 254684 & 69.1 \\
\hline 24 & Sinanoğlu-1 & 4258107 & 255078 & 69.2 \\
\hline 25 & Okşanlar kuyusu & 4258533 & 255946 & 71.5 \\
\hline 26 & Sanjet kuyusu & 4260175 & 259155 & 76 \\
\hline 27 & Yaşarlar kuyusu & 4258223 & 255551 & 78 \\
\hline 28 & AFS-11 & 4258473 & 257731 & 80 \\
\hline 29 & AFS-13 & 4258123 & 257428 & 80 \\
\hline 30 & Aldosan 1 kuyusu & 4256163 & 248977 & 80 \\
\hline 31 & Aktürkler kuyusu & 4258782 & 260227 & 85 \\
\hline
\end{tabular}

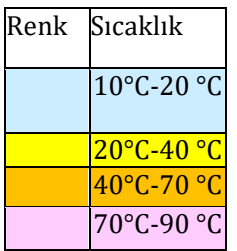

Sandıklı jeotermal alanında bulunan suların kaynak başında ölçülen bazı kimyasal özellik değerlerine göre, Sandıklı sıcak su kaynakları asidik karakter taşımaktadır (Tamgaç vd., 2008; Oğuz, 2011). Sandıklı jeotermal alanında yer alan kuyu ve kaynaklardan alınan su örneklerinin analiz sonuçlarına göre, beslenmenin alanın doğu, batı ve güney kesiminden alana doğru bu bölgelerden geldiği Tamgaç vd. (2008) tarafından belirtilmiștir.

Sandıklı jeotermal alanındaki bazı kuyulardan elde edilen verilerle oluşturulan sıcaklık dağılımı haritasına göre; mevcut sıcak su kuyularının olduğu bölgeler en yüksek sıcaklıklı alanlardır (Tamgaç vd., 2008). Başlangıçta DSI'den soğuk su ruhsatı olarak alınan 200-300 m derinliklere sahip ılık su kuyuları civarı bölgelerde suyun sıcaklığı $28-40^{\circ} \mathrm{C}$ arasında değişmektedir.

Bu çalışmada gerçekleștirilen İshak Özbek Koç 1 jeotermal kuyusuna ait statik sıcaklık ve basınç ölçümleri Tablo 2'de verilmiştir. İshak Özbek'e ait Afyon ili Koçhisar köyünde bulunan jeotermal sahasındaki Koç-1 jeotermal kuyusunda alınan kuyu içi ölçümleri Datacan firmasının 1,25”DXB elektronik kuyu içi sıcaklık basınç ölçüm ve kayıt cihazı ile yapılmıştır. Ölçümler yapılırken dakikada 40 metre halat çekebilen elektrikli wireline vinç kullanılmıştır. Yüzeyden itibaren 640 metreye kadar her 20 metrede bir, 640-900 metre arasında ise her 10 metrede bir, 1'er dakika beklenerek statik sıcaklık-basınç profili alınmıștır. Kuyu tabanı 900 metrede ölçülen sıcaklık $51,41^{\circ} \mathrm{C}$ dir. Kuyu tabanı basıncı 84,73 barg'dır. Yeryüzünden derine inildikçe jeotermal ısının arttığı ve 
kuyu içinde birkaç farklı gradyan gözlenmektedir.

Tablo 2. Çalışma alanındaki İshak Özbek Koç 1 kuyusuna ait statik sıcaklık ve basınç ölçümleri (Static temperature and pressure measurements of İshak Özbek Koç 1 well in the study area)

\begin{tabular}{|c|c|c|c|c|c|c|c|c|}
\hline $\begin{array}{c}\text { Derinlik } \\
\text { (m) }\end{array}$ & $\begin{array}{l}\text { Basınç } \\
\text { (bar) }\end{array}$ & $\begin{array}{c}\text { Sicaklık } \\
\left({ }^{\circ} \mathrm{C}\right)\end{array}$ & $\begin{array}{c}\text { Derinlik } \\
\text { (m) }\end{array}$ & $\begin{array}{l}\text { Basınç } \\
\text { (bar) }\end{array}$ & $\begin{array}{c}\text { Sicaklık } \\
\left({ }^{\circ} \mathrm{C}\right)\end{array}$ & $\begin{array}{c}\text { Derinlik } \\
\text { (m) }\end{array}$ & $\begin{array}{c}\text { Basınç } \\
\text { (bar) }\end{array}$ & $\begin{array}{c}\text { Sicaklık } \\
\left({ }^{\circ} \mathrm{C}\right)\end{array}$ \\
\hline 20 & 0.278168 & 20.085 & 398 & 36.312 .928 & 41.287 & 716 & 66.727 .077 & 47.371 \\
\hline 40 & 2.113 .654 & 25.753 & 417 & 38.296 .061 & 42.745 & 726 & 67.679 .987 & 47.537 \\
\hline 60 & 4.001 .597 & 27.463 & 437 & 40.175 .781 & 42.729 & 736 & 68.631 .455 & 47.492 \\
\hline 80 & 5.907 .887 & 29.151 & 457 & 42.080 .225 & 43.221 & 746 & 69.577 .683 & 47.718 \\
\hline 99 & 7.828 .236 & 30.961 & 477 & 43.977 .361 & 43.324 & 755 & 7.052 .452 & 48.144 \\
\hline 119 & 971.506 & 32.524 & 497 & 45.988 .639 & 43.505 & 765 & 71.479 .375 & 48.465 \\
\hline 139 & 11.622 .561 & 33.989 & 517 & 47.771 .837 & 43.769 & 775 & 72.420 .421 & 48.759 \\
\hline 159 & 13.543 .716 & 35.11 & 537 & 49.679 .572 & 44.143 & 785 & 73.359 .907 & 48.933 \\
\hline 179 & 15.429 .334 & 35.749 & 557 & 51.586 .111 & 44.494 & 795 & 74.314 .626 & 49.231 \\
\hline 199 & 17.319 .961 & 36.221 & 577 & 53.449 .115 & 45.043 & 805 & 75.269 .994 & 49.2 \\
\hline 219 & 19.320 .357 & 36.414 & 596 & 55.367 .341 & 45.306 & 815 & 76.213 .893 & 49.07 \\
\hline 239 & 2.113 .995 & 36.882 & 616 & 57.252 .795 & 45.849 & 825 & 77.165 .103 & 49.248 \\
\hline 258 & 23.056 .468 & 37.453 & 636 & 59.147 .397 & 45.98 & 835 & 78.102 .735 & 49.624 \\
\hline 278 & 24.967 .248 & 37.953 & 646 & 60.097 .859 & 46.175 & 845 & 7.904 .213 & 49.855 \\
\hline 298 & 26.862 .834 & 38.311 & 656 & 61.029 .399 & 46.304 & 855 & 79.982 .463 & 50.038 \\
\hline 318 & 28.766 .703 & 38.825 & 666 & 619.837 & 46.227 & 865 & 80.936 .088 & 50.221 \\
\hline 338 & 30.675 .788 & 39.503 & 676 & 62.939 .571 & 46.243 & 875 & 81.884 .507 & 50.347 \\
\hline 358 & 32.575 .114 & 40.032 & 686 & 63.898 .472 & 46.41 & 885 & 82.850 .134 & 50.671 \\
\hline 378 & 34.484 .091 & 40.55 & 696 & 64.847 .433 & 46.842 & 895 & 83.802 .224 & 50.892 \\
\hline 398 & 36.312 .928 & 41.287 & 706 & 65.783 .182 & 47.182 & 902 & 84.732 .465 & 51.41 \\
\hline
\end{tabular}

Tablo 3. DES'ler 1, 6, 21-24 için 1B ters çözümden elde edilen katman parametreleri (Layer parameters obtained from 1D inversion for VES' 1, 6, 21-24)

\begin{tabular}{|c|c|c|c|c|c|c|c|c|c|c|c|c|}
\hline \multirow{2}{*}{ DES No } & \multicolumn{8}{|c|}{ Katman parametreleri } & \multirow{7}{*}{ RMSE } \\
\cline { 2 - 13 } & \multicolumn{8}{|c|}{ Özdirenç (ohm.m) } & \multicolumn{7}{c|}{ Kalınlık (m) } \\
\hline 1 & 43.2 & 21.5 & 33.3 & 14.9 & 31.1 & 57.9 & 4.9 & 10.0 & 36.3 & 83.1 & 110.7 & 0.90 \\
\hline 6 & 38.4 & 15.7 & 8.7 & 192.5 & - & - & 17.7 & 86.7 & 131.3 & - & - & 0.68 \\
\hline 21 & 51.1 & 21.4 & 11.8 & 240.1 & - & - & 17.2 & 78.6 & 139.3 & - & - & 1.03 \\
\hline 22 & 13.4 & 22.0 & 13.5 & 20.5 & 98.8 & - & 5.1 & 15.0 & 51.0 & 379.7 & - & 0.38 \\
\hline 23 & 59.9 & 14.0 & 57.7 & 10.3 & 54.1 & 170.2 & 7.5 & 9.9 & 14.7 & 42.9 & 408.5 & 1.08 \\
\hline 24 & 40.1 & 16.3 & 23.8 & 96.7 & - & - & 9.5 & 58.8 & 208.4 & - & - & 0.39 \\
\hline
\end{tabular}

İkinci aşama olarak Sandıklı çalışma sahasında lokal olarak seçilen alanda altı noktada DAÖ yöntemi uygulanmıştır. Bu çalışmalarda düşük özdirenç zonlarının seviyeleri ve varsa altta sıcak su rezervuarı olabilecek kayaçların derinlikleri araştırılmıştır. Çalışma yapılan noktalarla ilgili değerlendirmeler; öncelikle kayaçların özdirençlerine göre ve sahanın jeolojik, topoğrafik yapıları da dikkate alınarak Schlumberger dizilimiyle bir DES çalışması gerçekleştirilmiştir.

Seçilen noktalarda, yukarıda özetlenen prensibe bağlı kalınarak yüzeyden aşağıya doğru kayaçların özdirenç değişimleri gözlenmiştir. DES noktalarında elde edilen bilgiler önce bilgisayar ortamında, daha sonra her ölçü noktasında elde edilen verilerin tek tek değerlendirilmeleri ile çalışma yapılan yerde sıcak kaynağa örtü olma ihtimali olan yerler ve seviyeler ile rezervuar kayaçları tespit edilmeye çalışılmıştır. Jeotermal ortamların özdirenç değerlerinin örtü olabilecek üst birimlerde ve daha çok da alttaki formasyonların özdirenç değerlerinden göreceli de olsa düşük değerlerde olması beklenir.

Sandıklı ilçesinin güneyinde yeralan Örenkaya kasabası civarında gerçekleștirilen çalışmada, Schlumberger elektrot dizilimi kullanılarak DES tekniği ile toplanan veri kümeleri 1B ve 2B olarak modellenmiștir (Şekil 4 ve 5). Şekil 6, K-G doğrultulu 6 DES noktasından elde edilen belirtiler ile bunların 1B değerlendirmesiyle hesaplanan belirtilerin bir karşılaştırmasını göstermektedir. 1B ters çözüm ile elde edilen katman parametreleri (özdirenç ve 
kalınlıklar) ile ortalama karekök hata (RMSE) değerleri de ayrıca Tablo 3'te sunulmuştur. 1B değerlendirmeden, genel olarak, 4-6 katman arasında ve görece düşük özdirenç değerleri sunan çözümler elde edilmiştir. Şekil 7 ise aynı DES noktalarına ait veri kümelerinin 2B ters çözümünden elde edilen yer elektrik kesitini göstermektedir (RMSE: 0.65). Buna göre, çalışma alanının bu bölümü yaklaşık $200 \mathrm{~m}$ derinlik seviyelerine değin yaklaşı 15 ohm.m değerinden küçük özdirenç değerleriyle temsil edilmektedir. 200-400 m derinlik seviyelerindeyse özdirenç 40-60 ohm.m arasında değişmektedir. Bu derinlik seviyesinden sonra ise özdirenç değerleri >80 ohm.m olan bir birim izlenmektedir.
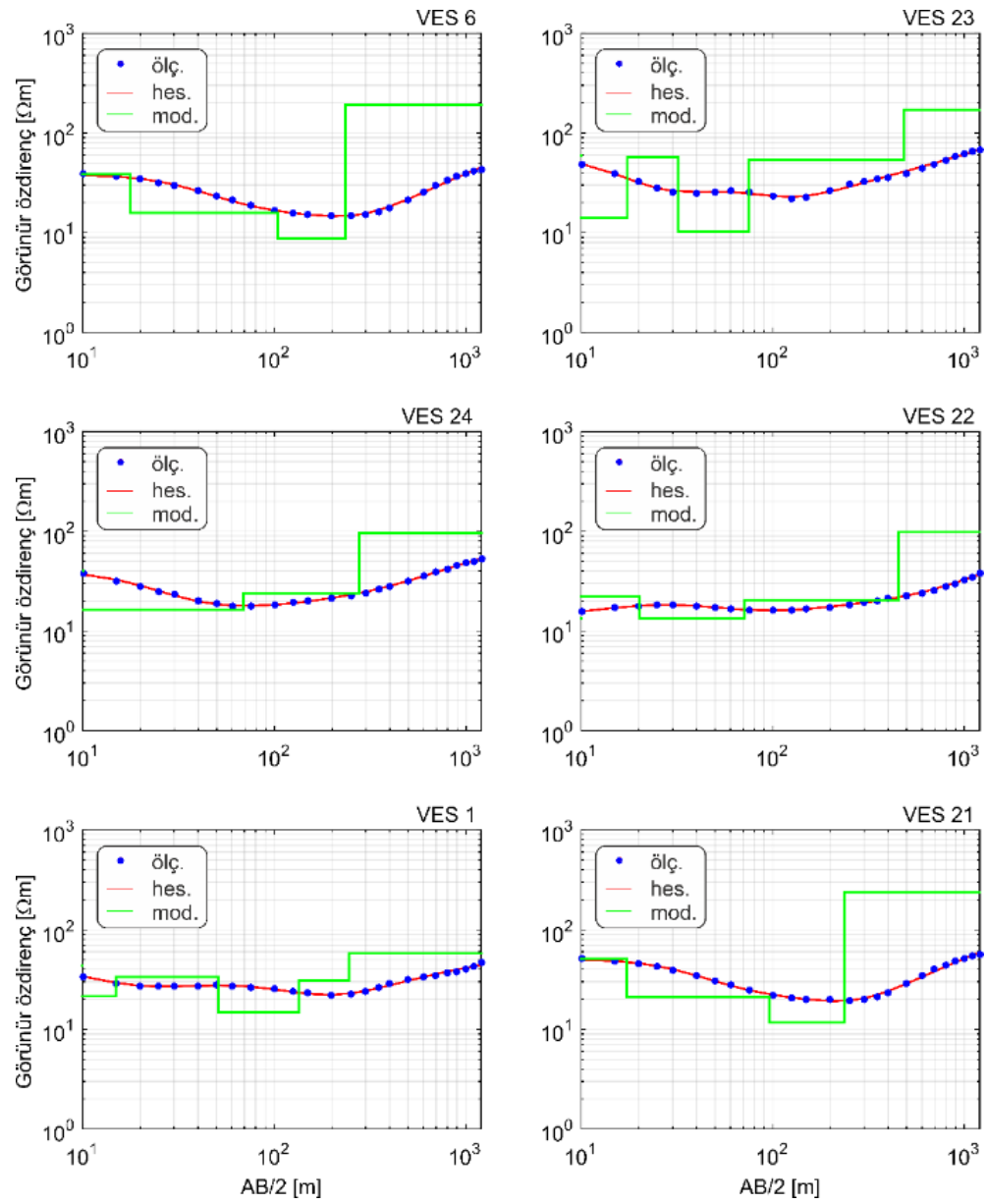

Şekil 6. Şekil 5 üzerinde görülen DES noktalarından elde edilen veri kümelerinin 1B ters çözüm tekniği ile değerlendirilmesiyle elde edilen modeller (Models evaluated by 1D inversion technique of data sets obtained from VES points shown in Figure 5)

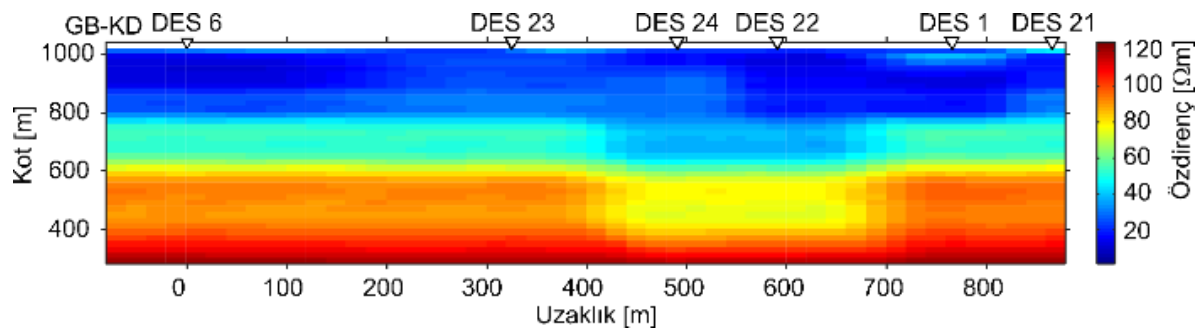

Şekil 7. DES verilerinin 2B ters çözümünden elde edilen yer elektrik kesit (The geoelectrical cross-section obtained from the 2D inversion of VES data)

\section{Sonuç ve Tartışma (Result and Discussion)}

Hem kuyulara ait fiziksel parametrelerin değerlendirilmesi hem de jeofizik arama çalışması (DES) yapılmış olan Sandıklı jeotermal sahasının (çalışma alanı), jeotermal saha tanımlamasının temel bileşenleri olan ısıtıcı kayaç, rezervuar kayaç ve örtü kayaç niteliğindeki litolojik grupları ve bunları kesen fay zonlarını bünyesinde barındıran bir saha olduğu kanaatine varılmıştır. Bu temel bileşenlerin varlığı, jeotermal bir potansiyelden söz edilebilmesinin kanıtlarıdır. 
Elde edilen tüm sonuçlar tek tek ele alınmış ve birbirleri ile karşılaştırılmıştır. Jeofizik çalışmalar neticesinde toplam 6 adet DES noktası veri kümesini içeren veriler ve sonuçların değerlendirilmesi sahanın jeotermal aktivitesinin fayların kesişme noktasında olabileceğini göstermiştir. K-KB yönlü ve doğuya doğru eğimli Hüdai hamamı fay segmenti ile kesişen ve kesiştiği yerde sıcak su çıkışlarının olduğu fay Örenkaya fayı olarak bilinmektedir. Jeofizik ölçümlerde özellikle P22-P24 ölçüm noktaları civarında elde edilen değerler örtü kayaç olarak kabul edilen Pliyosen-Miyosen birimlerde düşük özdirenç kapanımları olarak karşımıza çıkmaktadır.

Örenkaya kasabası civarından alınan DES ölçülerinin ters çözüm modellemesi ile oluşturulan kesit 6 noktada gerçekleștirilen bütün ölçülerin bir arada değerlendirilmesini sağlamıştır. Böylece jeolojik formasyonların yanal ve düşey yöndeki uzanımları, yeraltındaki su içeriği ve düşük özdirençli zonlar belirlenerek çalışma alanının jeotermal potansiyeli ortaya konmuştur. Özdirenç dağılımları incelendiğinde; Miyosen birimlerinin özdirenç değerlerinin temel birimlerden daha düşük olması beklenir. Oysa araştırma sahası grabenin ortalarına doğru derinleşmesine rağmen, özdirenç değerlerinin düşmesi sahanın P22-P24 noktalarının yer aldığı kesiminde yoğunlaşmıştır. Bu etkinin faya bağlı aktiveden kaynaklandığı düşünülmektedir. Bu çalışmadan elde edilen tüm sonuçlar dikkate alındığında alandaki 15 ohm.m'den düşük özdirenç değerleri gösteren bölgelerde sondajlar önerilmiştir.

Sahada yapılmış olan jeofizik etüt verilerinin mevcut tespitlerle entegre edilerek, entalpi (debi, sıcaklık) beklentisi optimum noktalarda yapılacak sondaj ya da sondajlarda alınacak birincil veriler ışığında netleşebilecektir. Ancak yakın çevredeki sahalar olan Afyon-Ömer ve Gecek sahalarında yakalanmış olan $80-135^{\circ} \mathrm{C}$ aralığındaki bir akışkan sıcaklığı, Sandıklı bölgesi için karakteristik sıcaklık beklentisinden uzaktır. Olası debiye ilişkin ise, net bir şey söylemek şu an için pek mümkün görünmemektedir. Sahanın genelinde yapılan gözlemler ve daha önce yapılan çalışmalara ilişkin elde edilen kısıtlı veriler çerçevesinde yüksek entalpi beklentisinin maksimum olacağı zonun derinlerde olduğu düşünülmektedir.

Sandıklı havzasındaki sığ ve derin kuyulardan alınan sıcaklık bilgileri değerlendirildiğinde; Sandıklı ilçe merkezinin batısındaki kuyulardaki sıcaklık değerlerinin çevredeki diğer alanlara göre yüksek olması (ortalama $65^{\circ} \mathrm{C}$ ) jeotermal kökenli rezervuarın bu bölgede yoğunlaştığını göstermektedir. Sandıklı jeotermal sahasındaki elde edilen bu değerler yapılacak olan $1000 \mathrm{~m}$ ve daha derin sondajlarda $50-60{ }^{\circ} \mathrm{C}$ arasında akışkan alınma ihtimalini güçlü tutmaktadır. Alandaki termal suların varlığı normalin üzerinde bir ısı akışının göstergesidir. Bu durumda ısıtıcı olarak gittikçe alçalan bir gelişimin son aşamalarında da olsa büyük olasılıkla volkaniklere bağlı bir ısı söz konusudur. Kısacası ısı kaynağı volkanizma sonrası hidrotermal aşamaya bağlı yüksek basınç altındaki emanasyonlardır.

\section{Teşekkür (Acknowledgement)}

Bu çalışma Süleyman Demirel Üniversitesi Bilimsel Araştırma Projeleri Koordinasyon Birimi tarafından SDÜ-BAP 4453-YL1-15 nolu proje kapsamında desteklenmiştir. Sorumlu Editör ve adı belirtilmemiş hakemlere teșekkür ederiz.

\section{Conflict of Interest / Çıkar Çatışması (Conflict of Interest)}

Yazarlar tarafından herhangi bir çıkar çatışması beyan edilmemiştir. No conflict of interest was declared by the authors.

\section{Kaynaklar (References)}

Afşin, M., 1991. Afyon-Sandıklı Kuruçay Ovası ve Hüdai Kaplıcalarının Hidrojeoloji İncelemesi. AÜ, Fen Bilimleri Enstitüsü, Doktora Tezi (yayınlanmamış), 330s.

Afşin, M., Canik, B., 1996. Hüdai (Sandıklı/Afyon) sıcak ve mineralli su kaynaklarının hidrojeoloji ve hidrokimyasal incelemesi ve kökensel yorumu, Yerbilimleri Dergisi (Geosound), 28, 69-86.

Aksever, F., 2011. Afyon Sandıklı Havzası Hidrojeoloji İncelemesi. Süleyman Demirel Üniversitesi Fen Bilimleri Enstitüsü, Yüksek Lisans Tezi, $231 \mathrm{~s}$, Isparta.

Balkaya, Ç., Kaya, M.A., Göktürkler, G., 2009. Delineation of shallow resistivity structure in the city of Burdur, SW Turkey by vertical electrical sounding measurements. Environmental Geology, 57, 571-581.

Balkaya, Ç., Göktürkler, G., Erhan, Z., Ekinci, Y.L., 2012. Exploration for a cave by magnetic and electrical resistivity surveys: Ayvacik Sinkhole example, Bozdag, Izmir (western Turkey). Geophysics, 77, B135-B146.

Bjorck, A., 1996. Numerical Methods for Least Squares Problems, SIAM, Philadelphia.

Candansayar, M.E, Başokur, A.T., 2001. Detecting small-scale targets by the 2D inversion of two-sided three-electrode data: application to an archaeological survey. Geophysical Prospecting, 49, 13-25.

Dean, W.T., Özgül, N., 1994. Cambrian rocks and faunas, Hüdai area, Taurus Mountains, southwestern Turkey. Bull. Instit. R. Sci. Naturale de Belgique-Science de la Terre, 64, 5-20. 
Dolmaz, M.N., 2014. İç Batı Anadolu'daki Sismik Olmayan Zon ile Sandıklı'nın Jeotermal Yapısı Arasındaki İlişki, Markakent Sandıklı Sempozyumu, Bildiriler Kitabı, 254-264, 16-18 Ekim 2014, Sandıklı-Afyonkarahisar.

Dolmaz, M.N., Ustaömer, T., Hisarli, Z.M., Orbay, N., 2005. Curie Point Depth variations to infer thermal structure of the crust at the African-Eurasian convergence zone, SW Turkey, Earth Planets and Space, 57, 5, 373-383.

El-Qady, G., Sakamoto, C., Ushijima, K., 1999. 2-D inversion of VES data in Saqqara archaeological area, Egypt. Earth, Planets and Space, 51, 1091-1098.

Erdoğan, B., Uchman, A., Güngör, T., Özgül, N., 2004. Lithostratigraphy of the Lower Cambrian metaclastics and their age based on trace fossils in the Sandıklı region, southwestern Turkey. Geobios, 37(3), 346-360.

Günay, Y., Derman, A. S., Kozlu, H., Göncüoğlu, C. M., Gül M. A., 1995. Stratigraphy of Lower Paleozoic in Southern Turkey. IGCP Project 351 -Early Paleozoic Evolution in NW Gondwana Excursion Guide Book, 3-9.

Güngör, T., Akay, E., Arslan, A., 2004. Deformation of the Sandıklı porphyroids, TÜBİTAK YDABÇAG Proje No. 102Y064, 1-39, Ankara.

Gürsu, S., Göncüoğlu, M. C., 2005. Batı Torosların (Sandıklı GB’sı, Afyon) Geç Neoproterozoyik ve Erken Paleozoyik Yașlı Birimlerinin Jeolojisi ve Petrografisi. MTA Dergisi, 130, 29-55.

Hamut, M.N., Șengüler, L., 2001. Afyon-Sandıklı (Hüdai) jeotermal sahası koruma alanları raporu. MTA Rap., No. 10458, Ankara.

Karamanderesi, İ.H., 2004. Sandıklı (Afyon) SANJET A.Ş. Sıcak su arama etüt raporu. JEM-2004-1. (SANJET A.Ş.).

Karamanderesi, İ.H., 2008. Sandıklı(Afyonkarahisar) SANJET A.Ş. AFS-14 nolu sondaj ve kuyu jeolojisi bitirme raporu 8.

Kaya, M.A., Özürlan, G., Balkaya, C., 2015. Geoelectrical investigation of seawater intrusion in the coastal urban area of Çanakkale, NW Turkey. Environmental Earth Sciences, 73, 1151-1160.

Koçyiğit, A., Cihan, M., Özacar, A., 2001. Dombayova ve Sandıklı (Afyon) grabenlerinin depremselliği ve kenar faylarının, kinematik analizi, TÜBİTAK YDABÇAG Proje No. 199Y007, 1-57, Ankara.

Kozlu, H., Göncüoğlu, M.C., 1995. Infracambrian units in Sandıklı area. (eds: Göncüoğlu M.C. and Derman A.S.) Guide Book to Early Palaeozoic in NW Gondwana. Turkish Association Petroleum Geologists, Special Publication, 2, 11-13.

Kozlu, H. Göncüoğlu, M.C., 1997. Stratigraphy of the Infracambrian Rock-Units in the Western Taurides and Their Correlation with Similar Units in Southern Turkey. (eds: Göncüoğlu M.C. and Derman A.S.) Early Palaeozoic in NW Gondwana. Turkish Association Petroleum Geologists Special Publication, 3,50-61.

Memiş, Ü., 2010. Afyon-Sandıklı Hüdai Jeotermal Alanının hidrojeokimyasal Özelliklerinin Belirlenmesi ve İz Element Kirliliğinin İncelenmesi. Süleyman Demirel Üniversitesi Fen Bilimleri Enstitüsü, Yüksek Lisans Tezi, 74 s., Isparta.

Müller, G., 1955. Heybeli (Kızılkilise) Kaplıcasının Hidrojeolojisi., 20, Ankara.

Oğuz, A., 2011. Sandıklı (Afyonkarahisar) Jeotermal Alanının Hidrotermal Alterasyon Özellikleri, Yüksek Lisans Tezi, Niğde Üniversitesi Fen Bilimleri Enstitüsü, 73s.

Ölmez, E., Karlı, R., Hamut, M.N., Karzaoğlu, H., 2000. Afyon-Sandıklı (Hüdai Kaplıcası) jeotermal alanı jeolojik etüt raporu. MTA Rap., No.10419, Ankara.

Öngür, T., 1973. Sandıklı (Afyon) Jeotermal Araştırma Bölgesine İlișkin Jeolojik Durum ve Jeotermal Enerji Olanakları. MTA Rapor No: 5520, Ankara (yayımlanmamıș).

Özgül, N., Bölükbaşı, S., Alkan, H., Öztaş, Y., 1991. Göller bölgesi ve Ispartanın Jeolojisi ve Stratigrafisi. TPAO arama grubu rapor no: 3028, 321 s., Ankara (yayımlanmamış).

Özpınar, Y., Çobanoğlu, İ., Bozkurt, R., 2002. Sandıklı zeolitik tüflerin petrografik petrokimyasal ve teknolojik özelliklerin incelenmesi, TÜBİTAK YDABÇAG Proje No. 198Y102, 1-268, Ankara.

Özpınar, Y., 2008. Sandıklı (Afyon) Yöresinde Șabazit ve Fillipsit Mineralleri İçeren Tüflerin Minerolojik Petrografik ve İyon Değiştirme Özellikleri ve Tarımda Kullanılması, GB Anadolu, Türkiye. MTA Dergisi, 137, 27-47.

Özürlan, G., Candansayar, M.E., Şahin, M.H., 2006. Deep resistivity structure of the Dikili-Bergama region, west Anatolia, revealed by two-dimensional inversion of vertical electrical sounding data. Geophysical Prospecting, 54, 187-197.

Ronner, F., 1956. Hüdai Hamamı termal kaynaklarına ve kaplıcalarına (Sandıklı- Afyon) dair muvakkat kısa rapor. M. T. A. Rap. No. 2493, Ankara.

Ronner, F., 1962. Sandıklı ovası çöküntüsü -Genç tektonik ve volkanik durumlar, MTA Dergisi, 59, 69-89, Ankara.

Seidel, K., Lange, G., 2007. Direct current resistivity methods. Environmental Geology - Handbook of Field Methods and Case Studies, pp. 205-237.

Şamilgil, E. 1964. Hüdai Hamamı (Sandıklı) hakkında jeolojik ve hidrojeolojik rapor. MTA Rap. No:3598, Ankara.

Tamgaç, Ö.F., Akan, B., Peker, B., Ünal, H., 2008. Sandıklı (Afyon) Jeotermal Alanının Koruma Alanları Etüt Raporu, MTA Rap. No. 2006-33-46, Ankara.

Uchida, T., Murakami, Y., 1990. Development of a Fortran Code for the Two-Dimensional Schlumberger Inversion. Geological Survey of Japan Open-File Report, No. 150, p 50.

Yenal, O., Osman, N., Kanan, E., 1975. Türkiye Maden Suları Ege Bölgesi, İstanbul Üniversitesi Tıp Fakültesi, Hidroklimatoloji Kürsüsü, İstanbul, 3, 335 s. 